\title{
INVESTIGATION OF THE SURFACE PROPERTIES OF TIN-COATED TIGAI4V ALLOY
}

Original scientific paper

\author{
Şengül Danişman ${ }^{1 *}$, Emin Ersoy$^{1}$, Canan Doğan ${ }^{1}$ \\ ${ }^{1}$ Erciyes University, Faculty Engineering, Turkey
}

UDC: $669.018 .6: 546.82$

https://doi.org/10.18485/aeletters.2021.6.4.5

\begin{abstract}
:
Titanium alloys are widely used in the aerospace industry due to their good mechanical properties. Especially Ti6Al4V alloy is preferred in machine parts that require specific strength in aerospace. However, the tribological properties of the Ti6Al4V alloy are poor and need improvement. It is possible to increase the life of Ti6Al4V alloys and improve their surface properties with various heat treatment and surface coating techniques. For this purpose, in this study, plasma nitriding heat treatment was first applied to the samples prepared from Ti6Al4V alloy. Then, TiN coating was carried out by the magnetron sputtering method. Surface roughness and surface hardness were measured before and after coating. Wear tests were performed with dry friction and room temperature conditions on Ti6Al4V alloys using the sliding velocity and normal load as variable parameters. The wear track widths, the weight loss of the samples, and the abrasive disc were measured. The steady-state sliding regime average friction coefficients were determined from the recorded friction forces depending on the sliding distance. Normal load - wear track widths, normal load - friction coefficient graphics were created. Load wear track width plots showed that the wear track widths on the TiN coated and uncoated samples increased with the load. The fact that the track width values of the uncoated samples with the same load and velocity values were higher than the TiN-coated samples showed that the TiN-coated samples had higher wear resistance. In addition, it was observed that the friction coefficient values in the uncoated samples under constant sliding speed were relatively higher than the TiNcoated samples.
\end{abstract}

\section{INTRODUCTION}

Titanium alloys are the most important materials used in industrial applications in the class of nonferrous metals [1]. Ti alloys are especially preferred in the aerospace industry due to their high corrosion resistance, high hot hardness and low-density advantages [1,2]. Design mass is essential to ensure optimum performance in aerospace applications. Titanium alloys are used to manufacture mechanical parts to create a design that can deliver the intended performance; it corresponds to almost half of the mass of materials

\section{ARTICLE HISTORY}

Received: 16.07.2021.

Accepted: 29.10.2021.

Available: 31.12.2021.

\section{KEYWORDS}

PVD, TiN Coating, Wear, Ti6A14V Alloy. used in aerospace [3-5]. In addition to its advantages, there are some disadvantages such as low wear resistance and high friction coefficient that limit the usage area [6,7]. Various heat treatments and surface coating techniques are used to eliminate these disadvantages and improve surface properties [8-13]. Studies to improve the surface properties of $\mathrm{Ti}$ alloys continue by using thin hard film coatings of PVD $[10,11]$ and CVD $[12,13]$. Various coatings with different properties are being developed according to application purposes $[6,7,11]$. 
TiN film coatings are thin ceramic coatings applied to various base materials due to their advantages such as high hardness, good thermal conductivity, low friction and good wear resistance $[10,11,14,15]$. They are also chemically stable and have good resistance to corrosion that can be caused by strong acids [16,17].

The popularity of TiN coating, which is important for use in cutting tool steels $[8,18,19]$, orthopedic implants [20,21], cold tool steels [22], aircraft compressor blades [7], is increasing year by year. At the same time, research on improving surface properties continues.

In TiN coatings obtained with PVD, the surface properties of the substrate material determine the properties of the coating [23]. In the study performed on aircraft compressor blades [7], it was observed that the $\mathrm{Ti}$ interlayer coating applied before the TiN coating was effective on the TiN/Ti multilayer coating strength [7]. The wear resistance of $\mathrm{TiN}$ coatings depends on good adhesion with the substrate. Otherwise, shear wear occurs at metal-to-metal contact [6].

When the wear behavior of TiN coating by cathodic arc deposition on Ti alloy is examined, even if the coating is worn, it is stated that the friction coefficient remains low thanks to the tribo films formed during dry friction [24].

The wear resistance of TiN films coated on $\mathrm{Ti}$ alloy by plasma implantation method increased with the decrease in the friction coefficient. At the same time, it was observed that the friction couple's wear behavior was improved when SiC counter material was used [25].

In this study, since the main material (substrate) strength is important, plasma nitriding heat treatment was applied to the Ti alloy, which will be used with and without coating. The TiN coating process was carried out with the magnetic field sputtering method, one of the Physical Vapor Deposition (PVD) techniques vital in the industry. Wear properties, surface roughness and hardness values of TiN coated Ti6Al4V alloy and uncoated Ti6Al4V alloy were investigated and compared with each other. It was revealed that the surface properties and wear resistance of Ti6Al4V samples were improved with TiN coating.

\section{MATERIALS AND METHODS}

The chemical composition and properties of the Ti6Al4V alloy chosen as the substrate are shown in Table 1.
Plasma nitriding is an industrial surface hardening treatment for metallic materials. Ti6Al4V alloy samples used in this study were subjected to plasma nitriding heat treatment at $650^{\circ} \mathrm{C}$ for two hours before the coating process. All of the samples were plasma nitrided before coating. The plasma nitriding parameters are given in Table 2. Plasma nitriding is an industrial surface hardening treatment for metallic materials.

After plasma nitriding, a diffusion layer forms on the substrate and a white layer on top of the diffusion layer. Although the diffusion layer is integrated with the base material, the white layer is a very thin layer on the diffusion layer. For this purpose, grinding and polishing processes were applied to all samples before coating in the study. $45 \mu \mathrm{m}$ diffusion and 0-1 $\mu \mathrm{m}$ white layer thicknesses were obtained by plasma nitriding process.

\subsection{Coating Method: PVD}

The samples were prepared from Ti6Al4V alloy before coating, and surface grinding and polishing operations were performed on the alloys in order. Then they were cleaned via an ethyl alcohol bath to remove any contamination on the base material surface. Finally, the coating process was performed in the following steps:

- Prepared samples were placed in the vacuum chamber;

- After reaching the desired vacuum with vacuum pumps, argon gas was sent into the chamber, and working pressure was kept constant;

- Ion cleaning was performed to remove any contamination on the substrate materials' surface;

- Titanium interlayer coating was performed to provide better contact on the substrate material, reduce residual stresses between the coating and substrate material interfaces and provide better adhesion via removing the oxide layer on the surface of the substrate material;

- Experiments were performed according to the parameter. After the coating time was completed, current and voltage were stopped and the samples were left to cool.

The system has a stainless steel vacuum chamber $(600 \mathrm{~mm}$ in diameter and $800 \mathrm{~mm}$ in high) and two unbalanced planar magnetrons powered by two independent 12-kW D.C. generators. 
Table 1. Ti6Al4V material properties

\begin{tabular}{|c|c|c|c|c|c|c|c|c|c|c|}
\hline Elem. (\%) & $\mathrm{N}$ & $\mathrm{Fe}$ & $\mathrm{Al}$ & $\mathrm{V}$ & $\mathrm{C}$ & $\mathrm{Ti}$ & Mech. & Yield Mpa & Tensile Mpa & $\mathrm{E} \mathrm{GPa}$ \\
\hline Ti6Al4V & 0.007 & 0.06 & 6.11 & 4 & 0.01 & Bal. & Ti6Al4V & 795 & 860 & 110 \\
\hline
\end{tabular}

Table 2. Parameters of Plasma Nitriding Process

\begin{tabular}{|c|c|c|c|}
\hline \multirow{2}{*}{$\begin{array}{c}\text { Time } \\
\text { (hr.) }\end{array}$} & \multirow{2}{*}{$\begin{array}{c}\text { Temp. } \\
\left({ }^{\circ} \mathrm{C}\right)\end{array}$} & $\mathrm{Ar} / \mathrm{N}_{2}$ & \multirow{2}{*}{$\begin{array}{c}\text { Pressure } \\
(\mathrm{Pa})\end{array}$} \\
\cline { 3 - 3 } & & ratio & \\
\hline 1 & 650 & $1 / 3$ & 200 \\
\hline
\end{tabular}

This system consists of the vacuum chamber, control unit and pumps. The samples to be coated are suspended in the middle holders and rotated during coating, as shown in Fig.1.

As the coating process parameters, $5000 \mathrm{~W}$ target power, $80 \mathrm{~V}$ bias voltage were used in the experiment. In order to improve adhesion to the substrate, Ti coating was applied for 10 minutes. Then TiN coatings were obtained in 3 hours coating time. Substare material temperature is $130^{\circ} \mathrm{C}$ during deposition. The produced TiN coating thickness is $1.49 \mu \mathrm{m}$.

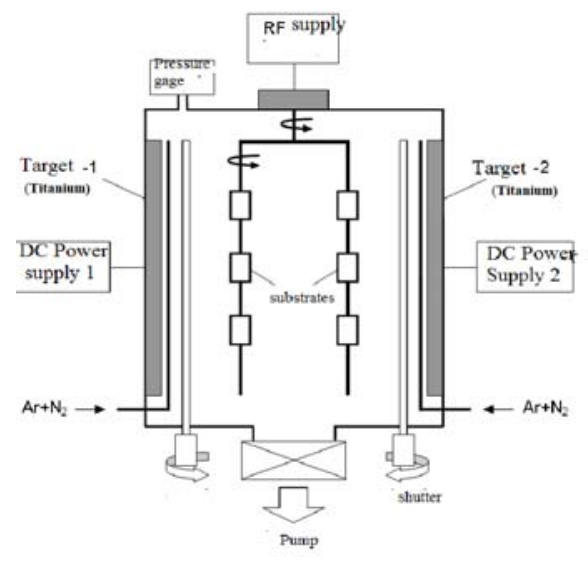

Fig. 1. Schematic view of the magnetron sputtering system used in this study

\subsection{Experimental Study}

Wear characteristics, surface roughness and hardness values of Ti6Al4V alloys with TiN coating and without TiN coating are compared to each other in the experiment environment created. Surface roughness values were determined with the Mitutoyo roughness device.

The hardness and elasticity modulus values were measured from the sample surfaces coated in the experimental environment with the CSEM nanohardness tester. The nanohardness of the coatings was determined with a square-based diamond Vickers tip $\left(\alpha=136^{\circ}\right)$ in CSEM nanohardness measuring device in accordance with the Oliver Pharr method [26]. In the coating hardness measurement, the penetration depth should not exceed one tenth of the coating thickness. Accordingly, the load was determined as $15 \mathrm{mN}$ in the experiment. Loading and unloading speeds were set as $30 \mathrm{mN} / \mathrm{min}$ for each measurement.

Plint Company's "T.E. 53SLIM multi-purpose friction and abrasion tester" was used in the wear tests by adapting to the pin-on-ring system. Samples made of Ti6Al4V alloy and abrasive elements made of DIN $100 \mathrm{Cr} 6$ are used. The chemical composition and mechanical properties of DIN Cr6 abrasive elements are shown in Table 3 below. Tribological tests were carried out using samples prepared in the size of $20 \times 65 \times 3 \mathrm{~mm}$.

Rings with a diameter of $26 \mathrm{~mm}$ and a height of $5 \mathrm{~mm}$, made of $100 \mathrm{Cr} 6$ material, are used as the abrasion element. In addition, TiN coated samples with Ti6Al4V base material and uncoated samples were used during pin-on-ring wear experiments. Shi et al. [27] revealed the difference between friction coefficient and wear resistance values of TiN coated Ti6Al4V alloy by working with $150 \mathrm{~N}$ load. In our study, 20, 50, $80 \mathrm{~N}$ loads were studied to reveal the wear resistance. The experimental systematic is shown in Table 4.

By using a separate abrasive element for each experiment, the experiments were carried out under different loads, at a constant sliding speed of $0.9 \mathrm{~m} / \mathrm{s}$ and under dry friction conditions at room temperature. Each of the samples and abrasive elements was cleaned with alcohol before abrasion experiments. Weight losses of samples and abrasive elements and the abrasion indentation widths on surfaces of the samples were measured after the experiments. It was weighed by an Ohaus brand precision balance with 1/10000 precision.

Steady-state sliding regime average friction coefficients were determined from the friction forces recorded by Picolog (Data Logger) depending on time, normal load-track width and normal load friction coefficient plots were drawn. 
Table 3. DIN $100 \mathrm{Cr} 6$ material properties

\begin{tabular}{|c|c|c|c|c|}
\hline \multicolumn{5}{|c|}{ Chemical Composition (\%) } \\
\hline $\mathrm{C}$ & $\mathrm{Si}$ & $\mathrm{Mn}$ & $\mathrm{Cr}$ & $\mathrm{Ni}$ \\
\hline 0.98 & 0.25 & 0.35 & 1.5 & 0.15 \\
\hline \multicolumn{4}{|c|}{ Mechanical Properties } \\
\hline \multicolumn{4}{|l|}{$\begin{array}{c}\text { It is known as bearing steel. Because it has high wear resistance, important mechanical properties can be } \\
\text { summarized as follows: Elasticity modulus } 207 \mathrm{Gpa} \text {, specific weight 7.85, density } 7850 \mathrm{~kg} / \mathrm{m}^{3} \text {, hardening } \\
\text { temperature } 830-870^{\circ} \mathrm{C} \text {, hardness after hardening } 64 \mathrm{HRC} .\end{array}$} \\
\hline
\end{tabular}

Table 4. Experiment systematic

\begin{tabular}{|c|c|c|c|}
\hline \multirow{2}{*}{ Coating Type } & \multirow{2}{*}{ Sample No } & \multicolumn{2}{|c|}{ Test parameters } \\
\cline { 2 - 4 } & & Normal Load(N) & Test Duration (mins) \\
\hline \multirow{3}{*}{ Uncoated } & 1.1 & 20 & 30 \\
\cline { 2 - 4 } & 1.2 & 50 & 30 \\
\cline { 2 - 4 } & 1.3 & 80 & 30 \\
\hline \multirow{2}{*}{ TiN } & 2.1 & 20 & 30 \\
\cline { 2 - 4 } & 2.2 & 50 & 30 \\
\cline { 2 - 4 } & 2.3 & 80 & 30 \\
\hline
\end{tabular}

\section{RESULTS AND DISCUSSION}

The average surface roughness values of the samples were made by taking two measurements from each sample and the data obtained were given in Table 5.

When the surface roughness values obtained from the samples made of Ti6Al4V alloy were examined, it was determined that the surface roughness of the TiN coating was greater than the uncoated material.

The hardness of Ti6Al4V alloy samples was measured under $30 \mathrm{mN}$ application load after heat treatment, with a hardness value of $807.314 \mathrm{HV}$ and an elastic modulus of $206.1 \mathrm{GPa}$. After the TiN coating process to the samples, the hardness and elasticity modulus values were measured from the sample surfaces under the application load of 15 $\mathrm{mN}$ by using nanohardness test device. Coated and uncoated measured values are given in Table 6 .

Not only the coating material but also the properties of the substrate material affect the properties of the coating [6-8]. For this reason, the hardness value of the substrate material has been increased by plasma nitriding on heat treatment. Lepicka et al. obtained the hardness value of the TiN coating as $2753 \mathrm{Hv}$ in their study which they deposited TiN on the Ti6Al4V alloy [24]. W.J. Chau et al. examined the hardness of the TiN coating depending on its thickness and found it to be 33 $\mathrm{GPa}[28]$. In our study, the samples that we applied hardening with plasma nitriding heat treatment and coated with TiN had a $27 \%$ higher hardness value.

In addition, hardness $(\mathrm{H})$ and modulus of elasticity $(E) ; H / E$ and $H^{3} / E^{2}$ ratios are important parameters that show the wear resistance of the coating [24]. The magnitude of these ratios indicates that the coating has a high resistance to wear [24]. High H/E ratios obtained due to measured values show that the TiN coating has a significant effect on the wear resistance of the alloy, as seen in Table 6 .

Table 5. Average surface roughness values of samples made of Ti6Al4V material

\begin{tabular}{|c|c|c|c|}
\hline $\begin{array}{c}\text { Coating } \\
\text { Type }\end{array}$ & $\begin{array}{c}\text { Sample } \\
\text { No }\end{array}$ & $\begin{array}{c}\text { Surface } \\
\text { roughness } \\
(\mu \mathrm{m})\end{array}$ & $\begin{array}{c}\text { Average } \\
\text { Surface } \\
\text { Roughness } \\
(\mu \mathrm{m})\end{array}$ \\
\hline \multirow{3}{*}{ TiN } & 2.1 & 0.375 & \multirow{2}{*}{0.613} \\
\cline { 2 - 3 } & 2.2 & 0.845 & \multirow{2}{*}{0.526} \\
\cline { 2 - 3 } & 2.3 & 0.62 & \multirow{2}{*}{0.526} \\
\hline \multirow{3}{*}{ Uncoated } & 1.1 & 0.52 & \\
\cline { 2 - 3 } & 1.2 & 0.54 & 0.52 \\
\cline { 2 - 3 } & 1.3 & \multicolumn{2}{|c}{} \\
\hline
\end{tabular}

In Fig.2, the coated and uncoated surface roughness, hardness and elastic modulus values of the samples made of Ti6Al4V alloy are graphically shown and compared. As seen in Fig.2, the hardness and modulus of elasticity values of the TiN coated sample increased compared to the uncoated sample. 
Table 6. Hardness and elastic modulus values of TiN coated Ti6A14V and uncoated Ti6A14V samples

\begin{tabular}{|c|c|c|c|c|}
\hline Coating Type & Hardness(HV) & $\begin{array}{c}\text { Elasticity Module } \\
(\mathrm{GPa})\end{array}$ & $\mathrm{H}_{\text {coated }} / \mathrm{E}_{\text {coated }}$ & $\mathrm{H}_{\text {coated }}{ }^{3} / \mathrm{E}_{\text {coated }}{ }^{2}$ \\
\hline TiN & 3513.7 & 493.16 & 7.124868 & 178368.5772 \\
\hline Uncoated & 807.314 & 206.1 & 3.917098 & 12387.15203 \\
\hline
\end{tabular}

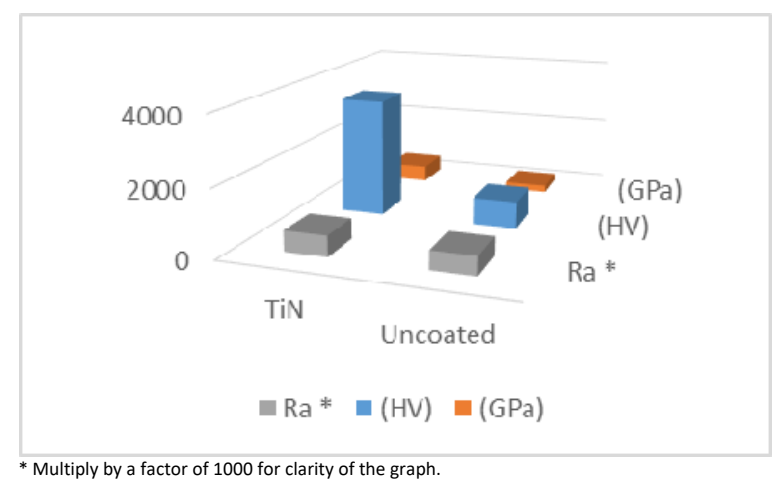

Fig. 2. Average surface roughness, hardness, and modulus of elasticity plot

The weight loss, wear track width, and friction coefficient values in the sample and the abrasive element resulting from the wear test are given in Table 7. The lowest friction coefficient value obtained from the TiN coated sample was 0.1124.

In Fig.3, weight losses, friction coefficients and wear track widths of TiN coated and uncoated samples with Ti6Al4V base material under different loads are compared to each other depending onthe coating type. The TiN coating reduces the friction coefficient compared to uncoated [24]. As seen in Fig.3, wear tests performed at different loads revealed that the friction coefficient decreased depending on the load [29].
When working at a load of $50 \mathrm{~N}$, the friction coefficient values in uncoated samples are higher than in coated samples. However, since the coating wears under $80 \mathrm{~N}$ loading, it is seen that there is no significant change in the friction coefficient compared to uncoated samples. Even if the coating is worn, it shows resistance thanks to the non-abrasive side areas. This wear is visible from the trace width images. The weight loss values of the uncoated samples were found to be relatively higher than the TiN coated samples.

Images of the wear track widths of the coated and uncoated samples under $20 \mathrm{~N}, 50 \mathrm{~N}$, and $80 \mathrm{~N}$ loads are shown in Fig.4, 5, and 6.

As shown in Table 7, the wear track width increases as the applied load increases. It was observed that the coated samples have a smaller wear track width at the same load values than uncoated samples track width values.

According to the wear test results performed at a load of $50 \mathrm{~N}$, the wear track width of the TiN coated sample was $24.2 \%$ less than that of the uncoated Ti alloy.

When the track widths obtained from the wear tests under different normal loads were examined, it was observed that the load had a significant effect on the wear resistance of the coated and uncoated samples.

Table 7. Experiment results

\begin{tabular}{|c|c|c|c|c|c|}
\hline \multirow{3}{*}{ Coating Type } & \multirow{3}{*}{ Sample No } & \multicolumn{4}{|c|}{ Experiment results } \\
\hline & & \multicolumn{2}{|c|}{ Loss of Weight (mg) } & \multirow{2}{*}{$\begin{array}{c}\text { Track Width } \\
(\mathrm{mm})\end{array}$} & \multirow{2}{*}{$\begin{array}{c}\text { Friction } \\
\text { Coefficient }\end{array}$} \\
\hline & & Sample & Wear Element & & \\
\hline \multirow{3}{*}{ Uncoated } & 1.1 & 5,3 & 0,7 & 4,6 & 0,1430 \\
\hline & 1.2 & 22,44 & $\begin{array}{l}3 \\
, 4 \\
\end{array}$ & 6,2 & 0,1347 \\
\hline & 1.3 & 24,6 & 3,5 & 6,5 & 0,1318 \\
\hline \multirow{3}{*}{$\mathrm{TiN}$} & 2.1 & 1,4 & 1,9 & 3,1 & 0,1924 \\
\hline & 2.2 & 7,6 & 2,8 & 4,7 & 0,1124 \\
\hline & 2.3 & 23,6 & 4,4 & 6,25 & 0,1144 \\
\hline
\end{tabular}




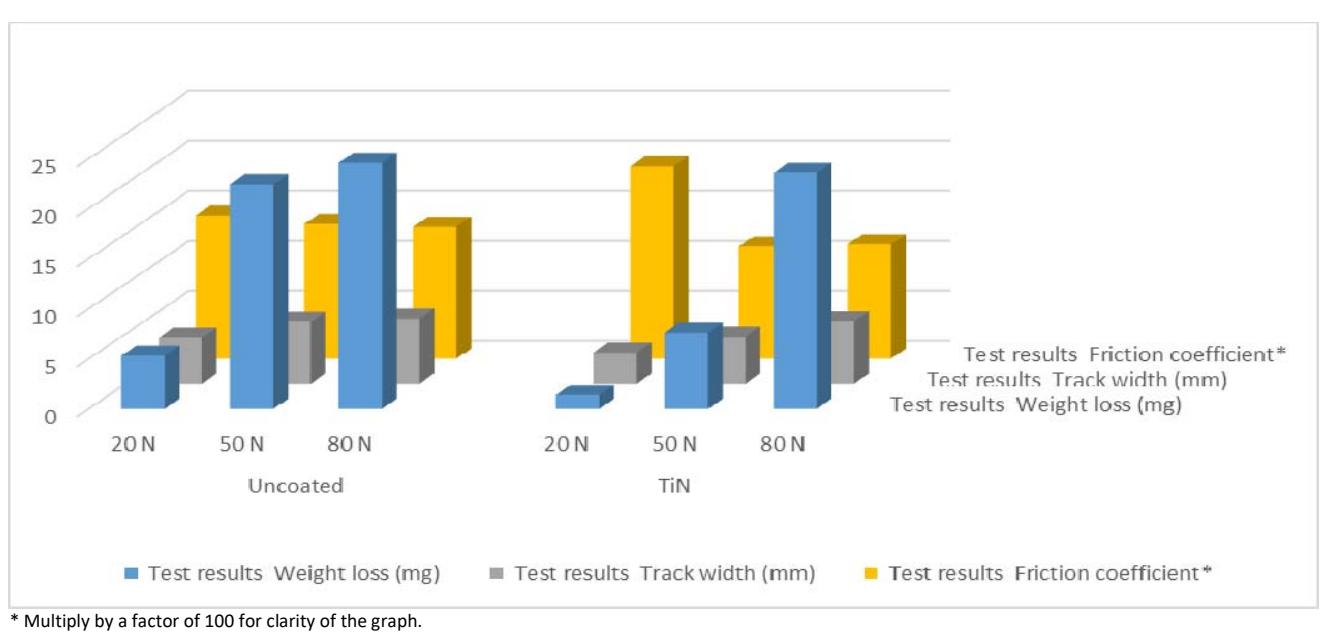

Fig. 3. Weight Loss, Track Widths and Friction Coefficients of Coated and Uncoated Ti6AI4V Samples at Different Forces

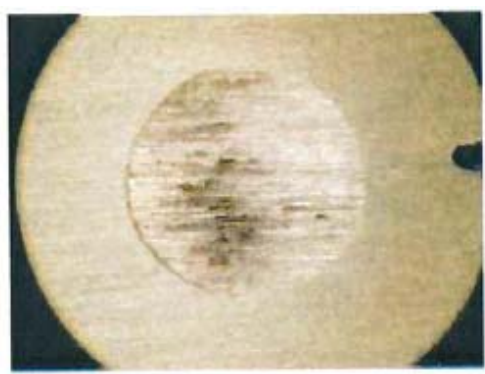

(a)

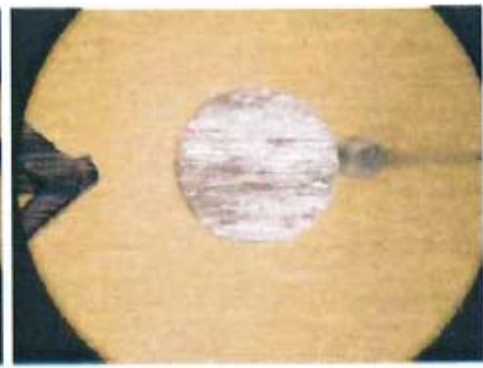

(b)

Fig. 4. Track widths occurring under $20 \mathrm{~N}$ normal loading a) Uncoated b) TiN coated

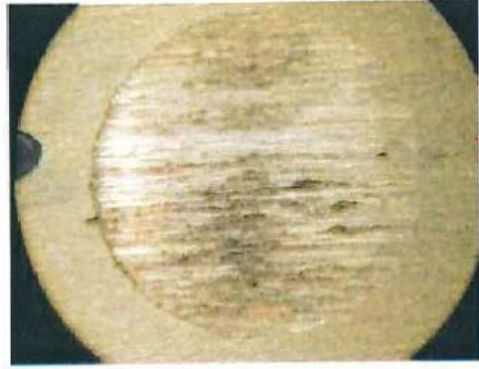

(a)

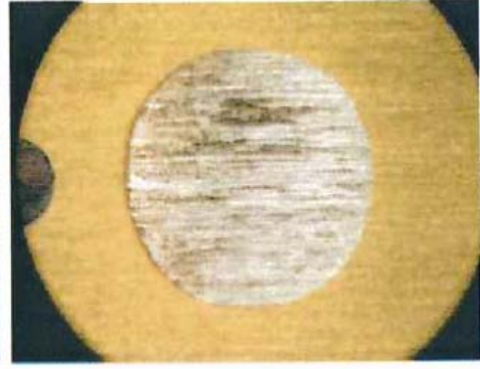

(b)

Fig. 5. Track widths occurring under $50 \mathrm{~N}$ normal loading a) Uncoated b) TiN coated

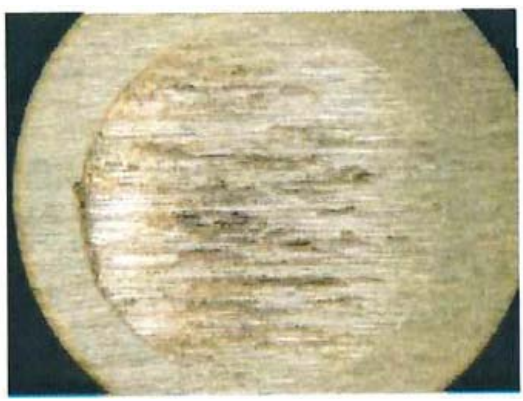

(a)

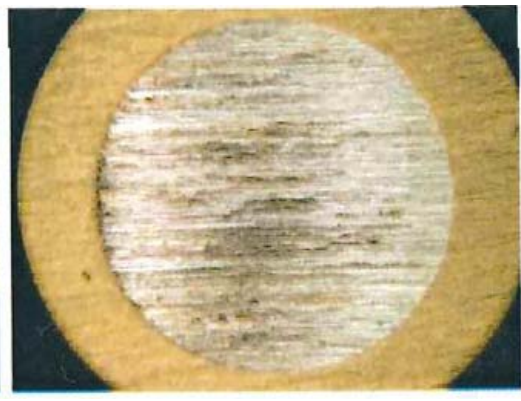

(b)

Fig. 6. Track widths occurring under $80 \mathrm{~N}$ normal loading a) Uncoated b) TiN coated 


\section{CONCLUSION}

It was determined that the TiN coated sample has the highest hardness value as 3513.7 HV when the hardness values of the samples made of Ti6Al4V alloy are compared according to uncoated. In addition, when the comparison is made in terms of elastic modulus, TiN had the highest value. It is seen that the hardness value is increased significantly after the TiN coating process.

At the same load values, the wear track width values in the uncoated samples were more significant than the TiN coated sample. This result reveals that the coated samples have a higher wear resistance value.

When the wear test data obtained from the samples made of Ti6Al4V alloy were examined, it was seen that the wear track widths on the samples were homogeneous and almost parallel to each other.

Therefore, wear track widths are taken into account as a measure of the amount of wear in the samples from the test results.

In terms of wear resistance, it was observed that the weight loss was also reduced with TiN coating.

\section{NOTE}

The abstract of this paper is published at the $10^{\text {th }}$ International Conference on Tribology BALKANTRIB '20 organised in Belgrade, on May 2022, 2021.

\section{REFERENCES}

[1] M. Balasubramanian, V. Jayabalan, V. Balusubraminian, Modeling Corrosion Behavior of Gas Tungsten Arc Welded Titanium Alloy. Transactions of Nonferrous Society of China, 17 (4), 2007: 676-680.

https://doi.org/10.1016/S10036326(07)60155-1

[2] Chetan, B. C. Behera, S. Ghosh, P. V. Rao, Wear behavior of PVD TiN coated carbide inserts during machining of Nimonic 90 and Ti6Al4V superalloys under dry and MQL conditions. Ceramics International, 42 (13), 2016: 14873-14885.

https://doi.org/10.1016/j.ceramint.2016.06.1 $\underline{24}$

[3] E.O. Ezugwu, Key improvements in the machining of difficult-to-cut aerospace süper alloys. Int. J. Mach. Tools Manuf., 45, 2005: 1353-1367.

https://doi.org/10.1016/j.ijmachtools.2005.02 .003

[4] E.O. Ezugwu, J. Bonney, Y. Yamane, An overview of the machinability of aero-engine alloys. J. Mater. Process. Technol. 134 (2), 2003: 233-253.

https://doi.org/10.1016/S09240136(02)01042-7

[5] D. Dudzinski, A.Devillez, A. Moufki ,D. Larrouquère, V. Zerrouki, J. Vigneau, A review of developments towards dry and high-speed machining of Inconel 718 alloy. Int. J. Mach. Tools Manuf., 44 (4), 2004: 439-456.

https://doi.org/10.1016/S08906955(03)00159-7

[6] M.S. Libórioa, G.B. Praxedesb, L.L.F. Limab, I.G. Nascimentoa, R.R.M. Sousac, M. Naeemd,T. H. Costaa, S.M. Alvesa, Javedlqbale, Surface modification of M2 steel by combination of cathodic cage plasma deposition and magnetron sputtered MoS2TiN multilayer coatings. Surface\&Coatings Technology, 384, 2020: 125327. https://doi.org/10.1016/j.surfcoat.2019.1253 27

[7] Z. Sun, G. HE, Q. Meng, Y. LI, X. Tian, Corrosion mechanism investigation of $\mathrm{TiN} / \mathrm{Ti}$ coating and TC4 alloy for aircraft compressor application. Chinese Journal of Aeronautics, 33 (6), 2020: 1824-1835

https://doi.org/10.1016/j.cja.2019.08.015

[8] Santecchia E. et al. I., Hamouda A.M.S., Zalnezhad E., Musharavati F., Cabibboc M., Spigarelli S., Wear resistance investigation of titanium nitride-based coatings. Ceramics International, 41 (9), Part A, 10349-10379, 2015.

https://doi.org/10.1016/j.cja.2019.08.015

[9] Y. Tanno, A. Azushima, Effect of counter materials on coefficients of friction of TiN coatings with preferred grain orientations. Wear, 266 (11-12), 2009: 1178-1184. https://doi.org/10.1016/j.wear.2009.03.020

[10] J. Yue, G. Li, Microstructure and mechanical properties of TiAIN/Si3N4 nano-multilayers synthesized by reactive magnetron sputtering. J. Alloy. Compd., 481 (1-2), 2009: 710-713. https://doi.org/10.4028/www.scientific.net/A MR.79-82.489 
[11] J.C. Oliveira, A. Manaia, A. Cavaleiro, Hard amorphous Ti-Al-N coatings deposited by sputtering. Thin Solid Films 516 (15), 2008: 5032-5038.

https://doi.org/10.1016/j.tsf.2008.02.006

[12] J.C. Nable, S. Nosheen, S.L. Suib, F.S. Galasso, Atmospheric pressure chemical vapor deposition of titanium nitride on metal. Surf. Coat. Technol., 200(8), 2006: 2821-2826.

https://doi.org/10.1016/j.surfcoat.2005.02.171

[13] D.H. Kuo, K.W. Huang, A new class of Ti-Si-C$\mathrm{N}$ coatings obtained by chemical vapor deposition, Partll: low-temperature process. Thin Solid Films, 394 (1-2), 2001: 81--89.

https://doi.org/10.1016/S00406090(02)00333-4

[14] N. Fateh, G. A. Fontalvo, G. Gassner, C. Mitterer, Influence of high-temperature oxide formation on the tribological behavior of TiN and V.N. coatings. Wear, 262 (9-10), 2007: 1152-1158.

https://doi.org/10.1016/j.wear.2006.11.006

[15] C.L. Liang, G A. Cheng, R.T. Zheng, H P. Liu, Fabrication and performance of TiN/TiAIN nanometer modulated coatings. Thin Solid Films, 520 (2), 2011: 813-817. https://doi.org/10.1016/j.tsf.2011.04.159

[16] R. Dhanaraj, S.B. Mohamed, M. Kamruddin, K. Kaviyarasu, P.A. Manojkumar, Structural Properties of TiN Thin Films Prepared by R.F. Reactive Magnetron Sputtering. Materials Today: Proceedings 36 (2), 2021: 146-149.

https://doi.org/10.1016/j.matpr.2020.02.668

[17] E. Arslan, I. Efeoğlu, Effect of Heat Treatment on TiN Films Deposited by CFUBMS, Materials Characterization. 53 (1), 2004: 29-34.

https://doi.org/10.1016/j.matchar.2004.07.01 $\underline{1}$

[18] P.C. Jindal, A.T Santhanam, U. Schleinkofer, A.F. Shuster, Performance of PVD TiN, TiCN, and TiAIN coated cemented carbide tools in turning, Int. J. Refractory Metals Hard Mater., 17(1-3), 1999: 163-170.

https://doi.org/10.1016/S02634368(99)00008-6

[19] D.E. Wolfe, J. Singh, Microstructural evolution of titanium nitride (TiN) coatings produced by reactive ion beam-assisted, electron beam physical vapor deposition (RIBA, EB PVD). J. Mater. Sci., 34, 1999: 2997-3006.

https://doi.org/10.1023/A:1004668325924
[20] L. Lapaj, J. Wendland J. Markuszewski, A. Mróz, T. Wiśniewsk, Retrieval analysis of titanium nitride (tin) coated prosthetic femoral heads articulating with polyethylene. J. Mech. Behav. Biomed. Mater., 55, 2016: 127-139.

https://doi.org/10.1016/i.jmbbm.2015.10.012

[21] I. Gotman, E.Y. Gutmanas, Titanium nitridebased coatings on implantable medical devices. Adv. Biomater. Devices Med., 1, 2014: 53-73.

[22] S. Kumar, S.R. Maity, L. Patnaik, Effect of Heat Treatment and TiN Coating on AISI O1 Cold Work Tool Steel. Materials Today: Proceedings, 26 (2), 2020: 685-688.

https://doi.org/10.1016/j.matpr.2019.12.367

[23] Chen JY, Yu GP, Huang JH. Corrosion behavior and adhesion of ion-plated TiN films on AISI 304 steel. Mater. Chem. Phys. 65 (3), 2000: 310-315.

https://doi.org/10.1016/S02540584(00)00255-8

[24] M. Łępickaa, M. Grądzka-Dahlkea, D. Pieniakb, K. Pasierbiewiczc, K. Kryńskaa, A. Niewczasb, Tribological performance of titanium nitride coatings: A comparative study on TiN-coated stainless steel and titanium alloy. Wear, 422423, 2019: 68-80.

https://doi.org/10.1016/j.wear.2019.01.029

[25] G.J. Wan, N. Huang, Y.X. Leng, PYang, J.Y. Chen, J. Wang, H. Sun,Tin and Ti-O/Tin films fabricated by PIII-D for enhancement of corrosion and wear resistance of Ti-6Al-4V. Surf. Coat. Technol., 186 (1-2), 2004: 136-140.

https://doi.org/10.1016/i.surfcoat.2004.04.037

[26] S. Kumar, S.R. Maity, L. Patnaik, Friction and tribological behavior of bare nitrided, TiAIN and AICrN coated MDC-K hot work tool steel. Ceramics International, 46(2), 2020: 1728017294.

https://doi.org/10.1016/i.ceramint.2020.04.0 $\underline{15}$

[27] S. Baoming, H. Shiming, Z. Ping, X. Changen, G. Peng, F. Youyu, In-situ TiN Reinforced Composite Coatings Prepared by Plasma Spray Welding on Ti6Al4V. Materials Letters-Volume 276, 2020: 128093.

https://doi.org/10.1016/j.matlet.2020.128093

[28] W.J. Chou, G.P. Yu, J.H. Huang, Mechanical properties of TiN thin film coatings on 304 stainless steel substrates. Surface and coatings Technology, 149 (1), 2002: 7-13. 
https://doi.org/10.1016/S0257-

8972(01)01382-2

[29] S. Kumar, S. R. Maity, L. Patnaik, Effect of Tribological Process Parameters on the Wear and Frictional Behaviour of $\mathrm{Cr}-(\mathrm{Crn} / \mathrm{Tin})$
Composite Coating: An Experimental and Analytical Study. Ceramics International, 47 (2), 2021: 16018-16028.

https://doi.org/10.1016/j.matpr.2019.12.367 